\title{
Retraction Note: Ocean detection and Japanese trade vocabulary translation based on remote sensing image boundary characteristics
}

Yi Wei ${ }^{1}$

Published online: 22 November 2021

(c) Saudi Society for Geosciences 2021

Retraction Note: Arabian Journal of Geosciences (2021) 14: 1443

https://doi.org/10.1007/s12517-021-07735-7

The Editor-in-Chief and the Publisher have retracted this article because the content of this article is nonsensical. The peer review process was not carried out in accordance with the Publisher's peer review policy. The author has not responded to correspondence regarding this retraction.

The original article can be found online at https://doi.org/10.1007/ s12517-021-07735-7

Yi Wei

yiwei289@163.com

1 School of Foreign Languages and International Education, Chengdu Technological University, Chengdu 611730, China 